\title{
MAÍRA AZEVEDO: UMA INFLUENCIADORA DIGITAL NA REDE CIBERAXÉ
}

\author{
MAÍRA AZEVEDO: A DIGITAL INFLUENCER IN THE CYBERAXÉ NETWORK
}

\section{MAÍRA AZEVEDO: INFLUENCIADOR DIGITAL EN LA RED CIBERAXÉ}

\section{Lúcio André Andrade da Conceição ${ }^{1}$}

\begin{abstract}
RESUMO
O artigo apresenta parte de uma pesquisa sobre a rede ciberaxé, a rede de conteúdos sobre o universo religioso afro-diaspórico, que circula no ciberespaço, através de diferentes plataformas digitais. O texto estuda uma referência dessa rede, Maira Azevedo, influenciadora digital com notoriedade em várias plataformas virtuais, discutindo temas relacionados ao candomblé, mulher negra, dentre outros tópicos. Para realizar este estudo, foram utilizadas publicações da Tia Má, postadas no Facebook e dita numa entrevista semi-estruturada, feita com ela. Para suporte nas análises, os conceitos de virtualidade e subjetividade são acionados em diálogo, com a compreensão teórica de Exu, sob duas perspectivas: uma, enquanto símbolo que representa a comunicação, via ciberespaço, como sendo "boca que tudo come"; a outra, como fragmentos de pensamento de um coletivo e tradutor de uma compreensão de mundo fora dos cânones ocidentais.
\end{abstract}

PALAVRAS-CHAVE: Rede Ciberaxé, Tia Má, Candomblé, Ciberespaço.

\section{ABSTRACT}

The article presents part of a research about the cyberaxé network, the content network about Afro-diasporic religious universe, which circulates in cyberspace, through different digital platforms. The text studies a representative of this network, Maira Azevedo, Tia Má, a digital influencer with notoriety on various virtual platforms, discussing topics related to candomblé, black women, among others. To carry out this study, publications published on facebook and a semi-structured interview with her were used. To support the analyzes, the concepts of virtuality and subjectivity are triggered in dialogue with Exu's theoretical understanding from two perspectives: one as a symbol that represents communication via cyberspace, as being "mouth that eats everything"; the other as fragments of the thought of a collective and translator of an understanding of the world outside Western canons.

KEYWORDS: Cyberaxé Network, Auntie Bad, Candomblé, Cyberspace.

Submetido em: 15/01/2021 - Aceito em: 31/03/2021 - Publicado em: 12/07/2021

${ }^{1}$ Doutor pelo Programa de Doutorado Multiinstitucional e Multidisciplinar em Difusão do Conhecimento (UFBA), professor do Instituto Federal de Educação da Bahia (IFBA), Assogbá do Terreiro Vintém de Prata (BA). 


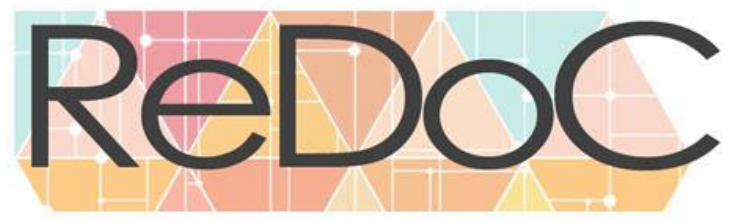

Revista Docência e Cibercultura

\section{RESUMEN}

El artículo presenta parte de una investigación sobre la red cyberxera, que representa la red de contenido sobre el universo religioso afrodiaspórico, que circula en el ciberespacio, a través de diferentes plataformas digitales. El texto estudia a una representante de esta red, Maira Azevedo, Tia Má, influencer digital con notoriedad en diversas plataformas virtuales, discutiendo temas relacionados con el candomblé, las mujeres negras, entre otros. Para la realización de este estudio se utilizaron publicaciones publicadas en facebook y una entrevista semiestructurada con ella. Para sustentar los análisis, los conceptos de virtualidad y subjetividad se disparan en diálogo con la comprensión teórica de Exu desde dos perspectivas: una como símbolo que representa la comunicación a través del ciberespacio, como "boca que se come todo"; el otro como fragmentos del pensamiento de un colectivo y traductor de una comprensión del mundo fuera de los cánones occidentales.

PALABRAS CLAVE: Red Ciberaxé, Tia Má, Candomblé, Ciberespacio

\section{INTRODUÇÃO}

O artigo apresenta parte de uma pesquisa sobre a rede ciberaxé ${ }^{2}$, representante da rede de conteúdos sobre o universo religioso afro-diaspórico, que circula no ciberespaço, em diferentes plataformas digitais, ou seja, são as experiências religiosas de matriz africana, criadas no Brasil e em outros países, compartilhadas pelas redes sociais virtuais. Neste texto, apresento o estudo sobre uma representante dessa rede, Maíra Azevedo, a Tia Má, que ganhou notoriedade nas plataformas virtuais e tornou-se uma influenciadora digital, discutindo temas, não só relacionados ao candomblé, mas também ao racismo, machismo, sexismo, mulher negra, intolerância religiosa.

Este trabalho analisou publicações selecionadas de Maíra Azevedo e uma entrevista semiestruturada realizada com ela, na qual conversamos sobre sua trajetória, até tornar-se influenciadora digital e suas posições sobre temas como: o papel da internet e seus limites, o ciberativismo, o candomblé na internet e sua compreensão sobre o que pode ser público e/ou privado no âmbito das redes sociais virtuais. Para suporte nas análises, os conceitos de virtualidade e subjetividade, são acionados em diálogo, com a compreensão teórica de Exu, sob duas perspectivas: uma, enquanto símbolo que representa a comunicação, via ciberespaço, como sendo "boca que tudo come"; a outra, como fragmentos de pensamento de um coletivo e tradutor de uma compreensão de mundo, fora dos cânones ocidentais.

\footnotetext{
${ }^{2}$ Ver mais em CIBERAXÉ: Redes formativas de difusão do conhecimento sobre candomblé , http://repositorio.ufba.br/ri/handle/ri/32425
} 
Revista Docência e Cibercultura

Maíra Azevedo é uma influenciadora digital que costuma se apresentar, usando vários adjetivos que, como ela mesma diz: "lhe representam mais não a resumem!". Todavia, fiz um recorte, em meio aos diversos papéis que ela exibe e foquei naqueles que me motivaram a escolhê-la para este estudo: sua condição de egbomi, em um terreiro de candomblé, em Salvador(BA) e de influenciadora digital, que traz, entre os assuntos para discussão nas redes, o combate ao racismo religioso, a intolerância religiosa contra os cultos afro-brasileiros e a socialização de informações que ajudam a desconstruir o imaginário negativo referente às práticas e aos praticantes das comunidades de axé.

\section{ITINERÂNCIA DO PESQUISADOR ENCARNADO À INFLUENCIADORA DO CIBERAXÉ}

A referência a condição de pesquisador encarnado é para me afirmar como sujeito que assume uma conduta epistemológica, a que as marcas corpóreas, sentimentais e de pertença do sujeito-pesquisador agregam potência criativa e insurgente contra os cânones científicos, pautados em uma razão pura e absoluta (PAZ, 2019, p.15). Partindo dessa perspectiva teóricametodológica descrevo como estabeleço relação com Maira Azevedo, a pessoa com mais de 84.000 inscritos no Youtube, 518.000 seguidores no Facebook ${ }^{3}$. Nestas duas plataformas, o nome e a imagem de Maíra Azevedo se intercalam com a de Tia Má, sendo que na segunda plataforma citada, usando de mais liberdade de posicionamento. Mais adiante voltarei a este assunto.

Conheci Maíra Azevedo no terreiro de Oxumaré, de onde ela é filha e eu sou neto, no mês de agosto de 2015, quando acontece o ciclo de festas para Oxumarê, Ewá, Ossain, Iroco e, finalmente, o Olubajé. Embora sejamos da "mesma água" e eu tenha mais tempo de iniciado do que ela, quando nos encontramos não estava frequentando, regularmente, o terreiro de Oxumaré, por isso não sabia que era filha dessa roça. Nesta época, ela ainda não tinha a visibilidade de hoje, nas redes sociais.

Não há nada de estranho nesse encontro tardio, sobretudo quando se trata de uma roça de candomblé antiga, como a nossa, onde a circulação de membros é intensa, com pessoas oriundas de muitas lugares, com diferentes atividades, que mantem relações de maior e menor frequência na comunidade. Vivenciar estas experiências de encontros e desencontros entre

\footnotetext{
${ }^{3}$ Estes números são de 25/07/2019
} 
filhos e netos de mesmo axé faz parte da rotina. O fato é que nos aproximamos durante os rituais, nos entrosamos na forma como executávamos as tarefas: imprimindo seriedade e disciplina nas atividades que nos eram atribuídas. Foi a partir desta sintonia no trabalho, que começamos a estabelecer uma simpatia um pelo outro, eu, em minhas funções como ogan e ela, ainda como Iyawo $\hat{o}^{4}$.

Além destes encontros esporádicos nos rituais na roça do Oxumaré, só mesmo na mídia que tenho notícias de Maíra. Primeiro na imprensa, quando trabalhava como repórter em uma empresa de jornalismo de Salvador; depois no Facebook, onde já exercia o ativismo com a temática racial, fazendo postagens refletindo sobre a condição singular de solidão vivida pela mulher negra. Logo depois ela aparecia com o bordão "Tia Má", "tia ama”, "tira o sapatinho, bota o pé no chão" e se tornaria uma referência entre os influenciadores digitais.

Foi me valendo dessa proximidade e sintonia construída no âmbito da roça de Oxumarê que fiz o convite para Maíra colaborar nesta pesquisa. A princípio, queria apenas autorização para usar suas postagens. Assim lhe enviei uma mensagem, pelo Whatsapp, fazendo este pedido. Ela respondeu: "Oxente, meu irmão! O senhor tem total autorização, me sinto, inclusive, honrada". A empatia em sua resposta me motivou a pensar em algo mais: por que não fazer uma entrevista?! A dúvida tinha a ver com a existência ou não de disponibilidade de sua parte. Fiz novo contato, desta vez, propondo o encontro. Mais uma vez ela demostrou um acolhimento valoroso e disponibilidade para me receber em sua casa. Nos preparativos para este entrevista, elaborei um questionário semi-estruturado. $\mathrm{Na}$ formulação destas questões tomei como referência uma entrevista que ela deu ao programa Perfil \& Opinião, da TVE Bahia, exibido em 26/09/2018; e seis postagens suas no Facebook.:

\section{“SOU PRETA, GORDA, PERIFÉRICA, MÃE SOLO, NORDESTINA, CANDOMBLECISTA E JORNALISTA!"}

São com estas referências que Maíra Azevedo costuma se apresentar nas entrevistas que faz, ou no show stand up: "Tia Má com a Língua Solta”, que vêm realizando em vários lugares do Brasil! São identidades, que perpassam sua trajetória de vida e a constituem, lhe acompanhando a qualquer lugar que adentre. São múltiplas faces que, nas telas das redes virtuais, encontram condições propícias para sofrer reconfigurações e até multiplicar-se,

\footnotetext{
${ }^{4}$ Nessa época ela ainda não havia cumprindo o Odulgê, ou seja, os sete anos de iniciação.
} 
aumentando ainda mais o leque de possibilidades de imagens de si. No entanto, nossa interlocutora, com todo este repertório identitário, estabelece limites, diante do contingente de seguidores que costumam lhe fazer inúmeros apelos e cobranças, às vezes, sobre o que deve e não deve ser, a respeito do que fazer e mostrar nos canais (este foi um dos assuntos que surgiram em nossa conversa!). Ela se resguarda, pondo algumas resistências, buscando manter um certo distanciamento e criticidade, além da autenticidade, para também não se render aos anseios e a fome insaciável do mundo virtual. Neste sentido, dissertar sobre sua história de vida nos ajuda compreender como ela consegue transitar, estabelecendo este limites na rede.

Maíra foi criada no bairro de Plataforma, que é um dos mais antigos do Subúrbio Ferroviário de Salvador (BA) e está situado à margem da avenida Suburbana. A casa de Maíra fíca do lado desta avenida que não é banhada pela Baía do Todos os Santos. Seguindo pela Suburbana, depois da loja automotiva Junior Rodas, na primeira entrada à direita, sobe a ladeira até o final e pergunta onde fica a casa de China (seu Pai), que todos conhecem. Esta foi a orientação que ela me passou em áudio mensagem. E de fato consegui chegar com ajuda das pessoas da comunidade. A casa de Maíra tem dois pavimentos, embaixo moram seus pais. Ela me recebeu, juntamente com seu filho Aladê Koman, a quem cobrou, com rigor: "como se faz diante de mais velho, no axé?". Aladê foi indicado para ogan, no terreiro Oxumarê, portanto, desde já, deve começar a realizar estes procedimentos. Passada esta etapa inicial das apresentações, me sento próximo dela, na sala, para assegurar uma boa gravação da conversa. Apresento-lhe, em linhas gerais, o teor das questões e, em seguida, começamos.

Embora tenha origem em bairro de periferia, onde a maioria dos moradores vivem com baixa renda e tem poucas oportunidades para manter-se nos estudos ou de projetar perspectivas melhores de crescimento social e econômico, Maíra Azevedo é uma exceção. Fez todo seu percurso formativo em instituições particulares, pois, seus pais queriam assegurar a formação superior para suas filhas e não as deixar à mercê das constantes greves que assolavam as universidades públicas da época. Ela fugia também a regra da maioria das famílias pobres desta região, porque sua ascendência não era de mulheres lavadeiras, empregadas domésticas ou que não tiveram acesso à escola; ela teve uma bisavó que foi empreendedora, proprietária de várias casas de aluguel; uma avó dona de casa e viúva de um funcionário público federal; e uma mãe, sra. Miralva Dias, professora. Contudo, esta condição diferenciada em relação aos demais moradores, em seu entorno, não lhe passaria desapercebida e a subsidiaria na jornada durante o curso de jornalismo, onde aprenderia a usar o poder da comunicação: 
“[...] eu sempre morei na periferia, mas sempre estudei em escolas particulares, mas sempre tive em espaços onde eu era a única preta do rolê, [....] a ameixa do pudim. Então eu comecei a entender, logo desde cedo que tinha lugares que para a população preta estar inserida era mais complicado. Então desde muito nova eu comecei a entender que eu precisava, eu queria entender que fenômeno é esse! [...] como é que no meu bairro todo mundo é negão, porque eu morava aqui na suburbana [...] na minha escola, eu tenho poucas pessoas pretas? [...] mesmo sem conseguir explicar estes conceitos eu conseguia entender, então quando eu entrei na faculdade de jornalismo e eu me tornei jornalista porque eu queria falar sobre isso"

Sua relação com o candomblé começa aos 7 anos, quando "um orixá se manifesta em meu corpo", diz Maíra. Na família educada dentro da religião católica, candomblé não era falado no cotidiano de casa. Embora, sua bisavó Bárbara de Iansã fosse a referência, quando se tocava nesta questão, ou quando a ouviam falar com "voz diferente", ou ainda quando necessitavam de algumas receitas milagrosas. Nesta época, um outro evento provocou grande estranheza na família, foi quando Maíra avisa a seu pai do falecimento de seu avô paterno, que morava no Rio de Janeiro, sem antes ter tido nenhum contato com estes familiares, mesmo por telefone, que era algo pouco acessível naquele tempo. Diante desta manifestação de comportamento atípica de Maíra, ganhou uma surra de seu pai que avaliou ter tido um comportamento inadequado; contudo, se constatou que existia algo acontecendo do qual, a família não compreendia, sobretudo por não vivenciarem em sua rotina.

Depois, aos treze anos, os eventos estranhos retornam. Maíra tinha incorporações, todo o tempo e estava sempre caindo em qualquer lugar, desmaiando. Foi levada, por sua mãe, a um centro espírita, na busca de tratamento e, finalmente, a um médico para um exame de ressonância. Este médico, diante do desespero de Dona Miralva, falou que ela precisava ser cuidada noutro lugar, que não era na medicina. Nós do candomblé costumamos dizer que não existem coincidências, contudo, coincidentemente, a irmã de Maíra começa um namoro com um rapaz, cujo pai é babalorixá.

Na casa deste senhor, Maíra faz seu primeiro bori, um ritual para fortalecimento da cabeça, do ori. Porém, ela não avalia como boa esta experiência, chegando, inclusive, a sair de lá com sentimento de ódio em relação ao candomblé. Tudo por conta do tratamento que recebeu. Ela era uma criança que, antes, nunca havia ficado tantos dias distantes dos pais. Após sete dias de ocorrida a cerimônia do bori, ela lembra de ter pedido para voltar para casa. O suficiente para que o babalorixá dissesse a sua Mãe que ela era uma pessoa ruim! Ao ser definida desta forma por alguém que, inicialmente, aos seus olhos, "tinha poderes mágicos, que tinham poder de enxergar sobre tudo", sentiu frustação. Maíra completa, contando que ao ouvir aquelas coisas, sobre si, quando estava em processo de formação da identidade, entendeu que 
foi vítima de julgamento, quando, em sua concepção, todos os lugares eram iguais e não podiam discriminá-la.

“[...] será que ele está vendo algo em mim, que eu não sei? Será que, de fato, eu não presto? Será que, de fato, eu sou alguém ruim e eu que não sei que sou esta pessoa ruim? Por que eu, inclusive, cheguei a acreditar que ele pudesse estar tendo uma vidência de entender que, de fato, eu era tipo uma vilã, uma marginal, e ele já estava anunciando para minha mãe ir se preparar comigo."

Esta relação conturbada com candomblé, expressa na narrativa de nossa entrevistada, não é inédita, ao menos para mim, que convivo com o povo-de-santo, há muito tempo. Neste universo, apesar dos valores relativos ao culto de orixás, voduns e inquíces, imprimirem certas posturas aos seus sacerdotes e sacerdotisas. Estes, antes de qualquer coisa, são pessoas com formações diversas e visões de mundo distintas que, de maneira particular, criam vínculos muito específicos com seus/suas "encantados/as", assim como absorvem estes princípios do culto da sua maneira. A partir destes vínculos, entre sacerdotes e sacerdotisas e as divindades do axé, vai se estabelecendo a configuração do espaço sagrado, da roça ou terreiro, no qual outras pessoas se agregam na construção e consolidação deste lugar. Partindo deste desenho simplificado, o comum a ser encontrado em qualquer casa de culto será a força que mobiliza as pessoas da comunidade em torno do sagrado. Ademais, é sempre tudo muito singular. A maneira como acontece a dinâmica das relações entre as pessoas no axé ou capacidade de tradução dos valores do candomblé para entes da comunidade, por suas lideranças ou mesmo a condução de rituais (cantigas, danças, comidas, vestuário etc.), tudo guardará sempre particularidades.

Neste sentido, o tratamento dispensado entre as pessoas neste cotidiano, tende também a ser uma incerteza, sem modelo ou homogeneidade, pois há sempre aqueles/as que sofrem mais ou menos por conta das interações. Estes são alguns dos fatores que tornam o contato inicial com o candomblé, uma experiência com inúmeras possibilidades, tanto positivas quanto negativas, tendo em vista que não existe uma forma única de acolhimento, variando sempre de lugar para lugar e, sobretudo, de pessoa para pessoa.

Outra questão a se pensar, com base também na narrativa de Maíra, é quando ela expressa indignação com o julgamento discriminatório e depreciativo sofrido, principalmente, por ter vindo de um sacerdote do candomblé, alguém até então de sua admiração. Fenômenos dessa natureza como queixas, reclamações, cobranças relacionadas a qualidade das inter-relações estabelecidas, no cotidiano do axé, tende a ocorrer mais e mais, dada ampla visibilidade social e, consequente, aumento atual da frequência da população em geral às casas de candomblé. 
Hoje são muitas pessoas buscando os cultos afro-brasileiros, não mais unicamente por motivos de saúde, como era mais comum no passado. São outras demandas, as quais exigem novas posturas dos membros das comunidades de axé. Demandas, por exemplo, emergentes de lutas sociais por respeito a igualdade de gênero, de raça e demais diferenças individuais. Demandas que resultaram de esforços históricos empreendidos pelos movimentos sociais, em especial, protagonizado pelas organizações negras no combate às diferentes manifestações do racismo. Um destas manifestações era o estigma negativo perpetrado às expressões culturais negras e, de forma mais agressiva, as religiões afro-brasileiras.

Hoje as condições são diferentes. Existe mais liberdade para ida aos terreiros de candomblé; deixou de ser uma atividade restrita aos adeptos, que antes fazia às escondidas, ou de forma discreta, como muitas vezes fiz, até início dos anos 90. Até esta época, eram poucos os curiosos que se lançavam a ir aos bairros de periferia de Salvador prestigiar estas cerimônias, as quais tinha como público certo a própria comunidade do entorno, além dos filhos e filhas da casa. A exceção era nos terreiros mais famosos e conhecidos, sobretudo por ter frequentadores famosos e pela publicidade como Gantois, Ilê Axé Opo Afonjá e Casa Branca. Entre estes curiosos/as tem a figura dos/as estrangeiros/as destas localidades como o estudiosos/as sobre religiosidade afro-brasileira, interessado/a em coletar dados para suas pesquisas.

Contudo, nesta atmosfera de desmistificação e maior trânsito aos terreiros de candomblé, o determinante é a mudança de perfil dos interessados/as no universo do culto. São pessoas que chegam, trazendo na bagagem uma leitura social, na qual temas como identidade, gênero, diferenças econômicas, direitos humanos, machismo, sexismo fazem parte de um conjunto de temas que não podem ficar de fora, ao adentrar qualquer espaço social que venha a conhecer; tensionando, portanto, as lideranças religiosas a ficarem mais atentas a este universo de espectros trazido por aquele/as que chegam nos portões do terreiro.

É importante lembrar que as roças de candomblé não se fizeram alheias as estas questões sociais. Afinal, sempre estiveram inseridas na sociedade, sofrendo as consequências de um modelo de sistema social calcado em práticas desiguais e orientadas pelo pensamento racista. No entanto, restava aos terreiros, diante deste sistema, se esforçarem para resguardar sua existência. Até porque os princípios culturais locais lhes asseguravam uma outra dinâmica interna, pelo menos enquanto não se havia adquirido a visibilidade social que atualmente as religiões afro-brasileiras adquiriram e que tem lhes imposto reformulações. Um exemplo do potencial dos valores estruturais destas comunidades, em contraponto ao pensamento dominante na sociedade a sua volta pode ser visto através da força que as mulheres negras e líderes religiosas exerceram nestes locais e no entorno das comunidades, algo excepcional em um contexto de sociedade, cujos governantes eram, majoritariamente, homens brancos. 


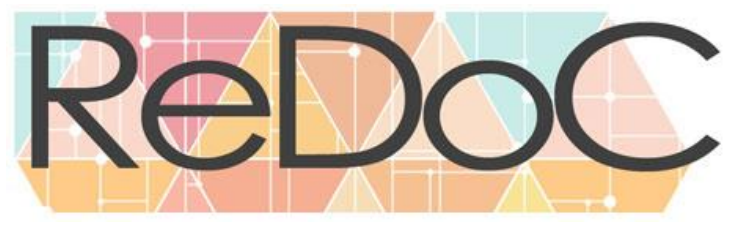

Revista Docência e Cibercultura

Mesmo com os conflitos iniciais com o candomblé, Maíra segue ao encontro com sua ancestralidade.

[...] A melhor coisa que aconteceu na minha vida foi eu ser feita na casa de Oxumare pelo meu pai-de-santo, eu acho que foi Oxum já dizendo não minha filha eu sei onde você vai nascer, eu sei onde você vai nascer pro axé, ... é porque eu tenho uma relação com meu babalorixá, que é uma relação acho que única, eu sou alguém que discorda de meu pai-de-santo, que diz a ele o que pensa, mas eu sei que a gente tem uma relação de cumplicidade, ele sabe que pode contar comigo e eu sei que posso contar com ele, mesmo que a gente não concorde sempre, e lá eu sinto de fato que estou na minha casa. [...]

Assim, em 2005, conhece a casa de Oxumarê, local onde viria a ser iniciada para Oxum, no ano de 2006, com o babalorixá Silvanilton da Encarnação, babá Pecê, com quem estabelece uma relação de respeito e satisfação, por ter nascido no axé de suas mãos, mas sem subserviência ou aceitação a todas as atitudes que toma, ou seja, discordando naquilo que ela compreende de forma diferenciada dele.

\section{VIRTUALIDADE REAL DE “TIA MÁ”}

Esta postura assumida por Maíra, perante seu babalorixá, é resultado, acredito, da formação política adquirida na atuação em organizações sociais nas quais se vinculou (estudantil, de negros/as, de mulheres etc.) para combate do racismo. Foram saberes que a subsidiaram no curso de jornalismo e, posteriormente, o exercício profissional no mundo da comunicação, iniciando como assessoria de jornalismo e, depois, como repórter. Na formação acadêmica desenvolveu a compreensão que: "a comunicação é espaço de poder e aí entendia que, naquele espaço ali, o que poderia fazer era dando voz e vez para pessoas negras, que, muitas vezes, são invisibilizadas e, até mesmo, esquecidas, anuladas”. O passo seguinte para o protagonismo nas redes sociais seria consequência de uma tendência geral de comportamento que influenciou toda a sociedade. Neste contexto, Maíra entende que a internet era um espaço em crescimento, do qual precisava se apropriar, dada a possibilidade de expansão de opinião, ainda que se defrontasse com posicionamentos contrários e perversos: "um espaço onde pode expor sua opinião e assegurar sua existência”. 
No começo, seus textos eram para refletir sobre a solidão vivida, mais intensamente, pela mulher negra, quando comparada as mulheres brancas. Fenômeno derivado do pensamento racista na sociedade, que construiu no imaginário dominante uma alegoria dicotômica entre mulher negra e a mulher branca, atribuindo a primeira a representação hipersexualizada, enquanto à segunda o modelo ideal para o casamento e a construção familiar. Filmes e novelas, reproduzidos pela indústria de massa para o entretenimento e a cultura, são um dos veículos que se encarregaram de disseminar este estereotipo distorcido, através das televisões e dos cinemas, desde quando surgiram para deleite da população brasileira. A esta condição de solidão se associam outras condutas, como os inúmeros relatos de violência física e psicológica sofrida (incluindo a grande quantidade de feminicídio); as narrativas de abusos sexuais e estupros, de abandono de filhos/as praticados por seus companheiros. Todos estes fatos afligindo, mais intensamente as mulheres negras, moradoras das periféricas e pobres.

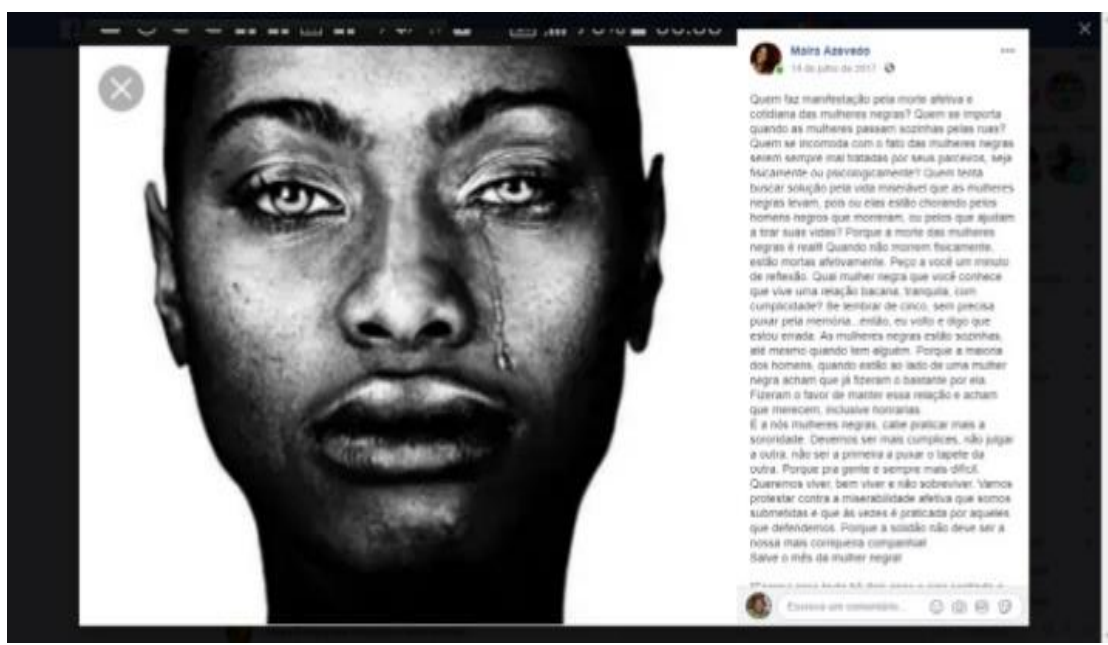

Figura 1: Rosto de mulher negra, mais texto

Fonte: Facebook, página de Maíra Azevedo, em 14/07/2017

Quem faz manifestação pela morte afetiva e cotidiana das mulheres negras? Quem se importa quando as mulheres passam sozinhas pelas ruas? Quem se incomoda com o fato das mulheres negras serem sempre mal tratadas por seus parceiros, seja fisicamente ou psicologicamente? Quem tenta buscar solução pela vida miserável que as mulheres negras levam, pois ou elas estão chorando pelos homens negros que morreram ou pelos que ajudam a tirar suas vidas. Porque a morte das mulheres negras é real!! Quando não morrem fisicamente, estão mortas afetivamente. Peço a você um minuto de reflexão. Qual mulher negra que você conhece que vive uma relação bacana, tranquila, com cumplicidade? Se lembrar de cinco, sem precisa puxar pela memória...então, eu volto e digo que estou errada. As mulheres negras estão sozinhas, até mesmo quando tem alguém. Porque a maioria dos homens, quando estão ao lado de uma mulher negra, acham que já fizeram o bastante por ela. Fizeram o favor de manter essa relação e acham que merecem, inclusive, honrarias. E a nós, mulheres negras, cabe praticar mais a sororidade. Devemos ser mais cumplices, não julgar a outra, não ser a primeira a puxar o tapete da outra. Porque 
pra gente é sempre mais difícil. Queremos viver, bem viver e não sobreviver. Vamos protestar contra a miserabilidade afetiva a que somos submetidas e que, às vezes, é praticada por aqueles que defendemos. Porque a solidão não deve ser a nossa mais corriqueira companhia!

Salve o mês da mulher negra

A publicação acima aconteceu, quando inúmeras atividades são realizadas, durante todo o mês de celebração do dia 25 de setembro, dia mundial da mulher Afro-latino-americana e Caribenha ${ }^{5}$. Esta postagem foi, originalmente, feita em 2015, mas é republicado pela autora, que diz continuar "sentindo a mesma dor". O texto, nesta ocasião teve 89 reações, 5 comentários e 11 compartilhamentos; não consegui acessar os números quando foi publicado na primeira vez. Entretanto, serve para ilustrar como esta internauta começou a ocupar o espaço nesta plataforma digital, trazendo narrativas sobre sua existência, garantindo que as dores sentidas por mulheres negras, como ela, não fossem invisibilizadas.

Ela utiliza linguagem simples, sem os termos rebuscados dos escritos acadêmicos. Narrando situações concretas, que são vividas, cotidianamente, nos lares dos bairros periféricos: mulheres negras sendo maltratadas, relações sem tranquilidade, de violência, sendo, portanto, porta voz de muitas e muitas que, diferente de Maíra, não desenvolveram a competência ou tiveram espaço para relatar suas dores. Por estas características, é uma publicação na qual outras mulheres negras se reconhecem e se veem representadas. Seja tratando de práticas explícitas de abusos e violência, ou como ela mesmo diz, com "as pequenas perversidades", do tipo "eu não quero que você saia sozinha, eu não quero que você vista determinada roupa", que tiram da mulher a liberdade cotidiana, a autonomia e a autoestima; ela foi fazendo estas reflexões em textos socializados na sua página pessoal da rede facebook.

A ideia da "Tia Má", não foi criar um personagem, outra pessoa, isto porque se trata da própria Maira Azevedo, só que se expressando de maneira mais espontânea, sem engessamentos ou melindres na linguagem. Ela lembra que foi na ocasião de uma paquera mal sucedida, de um rapaz que lhe parecia ser mais novo, onde ela respondeu aconselhando-o a melhorar na abordagem e, ao final, usou a expressão "tia ama", daí transformando para Tia Má. Outro fato é que, como ainda trabalhava em uma empresa jornalística na Bahia, de grande circulação no estado, achou prudente usar outro nome nos vídeos que começou a fazer

\footnotetext{
${ }^{5}$ No Brasil, oficializou-se a data em 2014, quando a então presidenta Dilma Rousseff sancionou a Lei no 12.987 determinando o Dia Nacional de Tereza de Benguela e da Mulher Negra.
} 
(inicialmente, sobre relacionamentos, mas depois sobre racismo, machismo, intolerância religiosa e demais pautas de interesse das populações negras) e assim, evitar riscos de associação indevida.

A Tia Má expressa a virtualidade real de Maíra Azevedo. Segundo Castell (1999, p.395), o real é aquilo que existe de fato, enquanto o virtual é uma percepção, via símbolos constituídos de acordo com a cultura e sujeitos a diferentes elaborações interpretativas. Este autor diz ainda que realidade e representação simbólica não se separam e que em todas as sociedades existem ambientes simbólico, através do qual elas atuam. O ciberespaço é este ambiente, atualmente, fruto da criação de um sistema de comunicação organizado pela integração eletrônica de todos os modos de comunicação, que faz nascer a virtualidade real, na qual novos símbolos circulam. A Tia Má é um destes símbolos, uma personagem que representa empoderamento e extroversão, cujo sucesso se dá pela destreza ao se valer de linguagem simples e direta para explorar temas complexos. Esta performance é veiculada pela linguagem dos vídeos, na qual é incorporado o estilo humorístico, competência descoberta, posteriormente, depois de perceber que já fazia, em função do aprendizado adquirido no seio familiar, onde todos costumam usar do sarcasmos e ironia nas conversas.

Uma virtualidade real que encontra na linguagem dos vídeos condições propícias para utilização de símbolos, segundo seus interesses. No uso da linguagem do dia-a-dia, direta, sem arrodeio, a qual qualquer pessoa, independente de formação educacional, consegue assimilar, está também na agilidade em transmitir as informações, pois são curtos com um ou dois minutos de duração, embora tenham vídeos que demandem mais tempo, principalmente, quando tratam de temas mais complexos e requerem um pouco mais de elaboração. São vídeos produzidos sem um planejamento prévio, de forma espontânea, seja no carro, em um engarrafamento ou antes de entrar em um evento ou ainda em casa, durante os afazeres ordinários, comum a qualquer pessoa, com ou sem maquiagem, bastando apenas que apareça o assunto que mereça fazer esta interlocução. Por fim, o estilo humorístico, descontraído da linguagem, capaz de mexer em assuntos sérios com sagacidade, provocando risos, mas sem perder a criticidade.

No programa Perfil \& Opinião ${ }^{6}$, exibido no canal da TVE - BA, no qual foi entrevistada em 26/09/2018, tem um momento em que Maíra conta um caso relacionado com os vídeos de Tia

${ }^{6}$ Link da entrevista: https://www.youtube.com/watch?v=ZdYORe7bv1I\&t=1210s 
Má. Ela foi abordada por uma de suas seguidoras, enquanto andava em um shopping de Salvador. Mas esta mulher, no primeiro momento, antes de abordá-la, lhe acompanhou por um tempo sem se apresentar, causando susto em Maíra. Após a surpresa do primeiro contato, explicou que vivia um relacionamento abusivo, há muito anos, mas não sabia como dar fim a ele. Daí começou a assistir os vídeos de Tia Má. Inicialmente, a seguidora disse ter sorrido bastante, mas depois chorou pois começou a se perceber nas mensagens, viu que era dela também que estava falando. Então, através destes vídeos, conseguiu buscar meios para sair da relação nociva na qual se encontrava.

Durante a minha entrevista, fiz uma pergunta pensando no esforço dos movimentos sociais negros, que, durante anos, vêm trabalhando para o fortalecimento da identidade negra, para que sua imagem seja vista como positiva e bonita. Este questionamento pautou-se no que acontece hoje no ciberespaço, com os recursos tecnológicos disponíveis, tornando o debate sobre identidade algo mais fluido, em função das possibilidades de o sujeito adotar múltiplas imagens de si nas redes sociais. Me interessava sua opinião, tendo vista que Tia Má, também poderia ser considerada como uma segunda imagem de Maíra Azevedo. Ao responder, ela vai chamar atenção, inicialmente, sobre o papel da rede social, que, para ela, é propositora da existência social. Em sua justificativa, Maíra citará o filme documentário "Ônibus 174"”, no qual um jovem negro sequestra um ônibus na zona sul do Rio de Janeiro e mantem passageiros reféns, durante quatro horas. No documentário, uma das primeiras exigências deste jovem foi a presença da impressa e da TV. Na argumentação de Maíra, mesmo sem saber se este rapaz tinha noção do papel da comunicação, sua vida foi mantida enquanto a imprensa televisiva o mantinha em audiência, vindo a ser alvejado, pela polícia, logo após tirá-lo do ar. Isto, em sua compreensão, é o que rede social faz, “ a rede social dá pra gente o poder da visibilidade, que pra gente sempre nos foi negado". Ela afirma que se hoje trabalha na TV, é por conta do aval conquistado nas redes sociais e cita a existência de várias mulheres negras que conquistaram seguidores na redes, se (auto) intitulando como símbolo de beleza.

\footnotetext{
${ }^{7}$ Lançado em dezembro/2002 (São Paulo), dirigido por José Padilha e Felipe Lacerda
} 


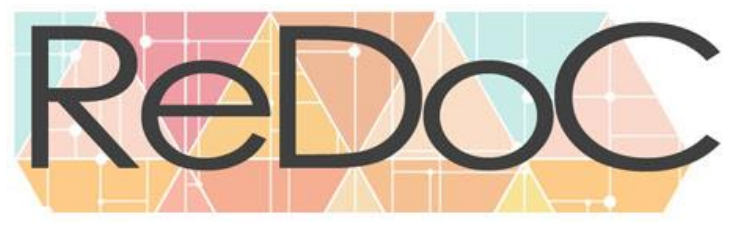

Revista Docência e Cibercultura

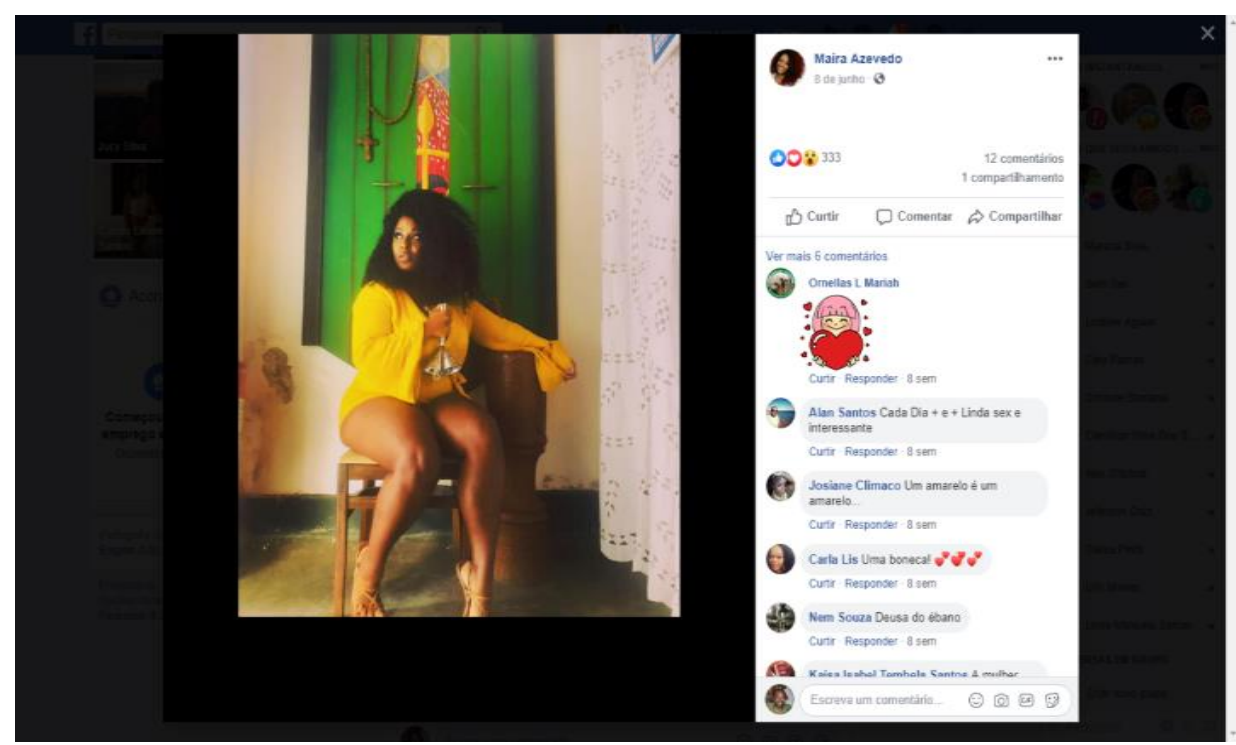

Foto 1: Maíra Azevedo sentada na cadeira

Fonte: Facebook, página de Maíra Azevedo, publicado em 08/06/2019.

As críticas aos modelos de beleza que comumente circulam nas revistas, nos programas de $\mathrm{TV}$, na publicidade, de um modo geral, é uma pauta antiga, mas amplamente combatida pelos movimentos de mulheres, em especial de mulheres negras, que denunciam a objetificação a que são condicionadas estas modelos, assim como o padrão de beleza que é estabelecido: mulher branca, magra, jovem e de curvas acentuadas. Uma tendência de comportamento que tem influenciado muitas jovens mulheres a se submeterem a um ritmo exagerado de condicionamento físico, nas academias de ginásticas ou ir ao extremo das intervenções cirúrgicas de estética, para aplicação de silicone e próteses, às vezes em condições insalubres, ou sem orientação profissional, tudo na busca do "corpo ideal". No caso de Maíra, que se sente bonita com suas formas, fora deste modelo estabelecido por esta indústria da estética, publica a foto 2 sem acrescentar nenhum comentário, mas pelo simples fato de estar se sentindo bela. Esta singela publicação, consegue promover uma quebra eficaz no dito padrão estético. Sua atitude não é fruto de nenhuma campanha publicitária, como já realizada por algumas empresas no ramo da estética que, conscientemente, adotam em suas políticas de marketing ações, pensando em público mais diversificado, que inclusive é tão economicamente ativo e consumidor como qualquer outro.

A atitude de Maíra representa o exercício de poder, o exercício de autonomia, de escolher como se mostrar, independente do que o outro possa dizer. Ao mesmo tempo, expressa 
discernimento sobre seu prestígio entre seguidores, afinal, é preciso ter um mínimo de convicção de que terá retorno positivo daqueles/as que a seguem. Isto tem a ver com a compreensão destes canais virtuais, enquanto produtores maquínicos de subjetividade, como citados por Guattari (1992). O potencial de veicular sentimentos, aspirações, desejos, permitiu a Maíra, através das redes socias, exibir seu corpo de mulher negra e gorda; ela faz isto em casa, não em um estúdio, tanto que aparece na parte de baixo do lado esquerdo da foto um trecho de parede sem pintura; ela usa apenas um batom e as roupas não fazem referência a nenhuma marca de grife; portanto, tudo traduz informalidade, os elementos simbólicos e linguagens corporais explicitadas são, ordinariamente, acessíveis e reproduzíveis a qualquer pessoa comum, gorda e negra como ela. Basta que se sinta bela!

Sibilia (2016) afirma que mudanças nos modos dos sujeitos interagirem, influenciadas por circunstâncias históricas, afetam o campo das subjetividades, como em um jogo intricado, múltiplo e aberto. Quando levamos este raciocínio para as socializações desenvolvidas no ciberespaço, percebemos o quanto isto pode assumir dimensões ainda mais complexas, dada a possibilidade de se virtualizar a realidade infinitamente, ou seja, de construir códigos para leitura da realidade. O que quero dizer com isto? Na entrevista, Maíra faz uma reflexão sobre a questão da representatividade nas redes sociais. Ela diz estar consciente das incertezas que sua visibilidade atual nas redes e na TV pode significar: "eu nunca deixei de tirar meu sapatinho e colocar o pé no chão". Mostrando-se atenta à perversidade do pensamento racista, ela não descarta a hipótese de se inventarem estratégias para não deixar pessoas negras, como ela, ficarem no sucesso de forma duradoura, sobretudo em espaços de poder, como na mídias comunicacionais.

Ainda em sua reflexão, Maíra, reconhece na rede social a possibilidade de seguir vivo, de perpetuar informações, memórias, imagens e sons referentes a lugares e pessoas. Ela então traz, como exemplo, uma postagem sobre Egbomi Cidália $^{8}$ : reconhecida, entre o povo-desanto por sua sabedoria dentro do candomblé, não era uma internauta, mas tem vários vídeos e imagens que fizeram dela e outros internautas postam em suas redes, com a intenção de demostrar uma falsa imagem de proximidade, mesmo sem sequer tê-la conhecido. Isto, na concepção de Maíra, é demonstração de como a rede social é um espaço de poder, de disputa, no qual quem não interage no ciberespaço pode ser usado/a para atribuir uma imagem de prestígio e poder a quem não tem e, assim, passar a ser visto perante os demais. Mas é a demonstração também do quanto esta rede de relações são vulneráveis a mudanças,

\footnotetext{
${ }^{8}$ Ela foi iniciada no terreiro dos Gantois, aos sete anos pela lyalorixáMeniniha do Gantois, a quem foi consagrada ao orixá Iroko. Ela faleceu em 20 de março de 2012.
} 
realinhamentos e transformações indicando o quanto Exu é uma força intrínseca na esfera do ciberespaço. Nada está dado em absoluto, existe sempre a relatividade que parte de quem olha sobre a tela. O corpo negro e gordo da postagem que encanta, gera vários "likes" e compartilhamentos, convive com os comentários depreciativos, racistas. Estão lado a lado, como em um baile de muitas máscaras.

\title{
O PRIVADO, O PÚBLICO, O SEGREDO E A VISIBILIDADE NO CIBERAXÉ: EIS A QUESTÃO!
}

Na postagem abaixo Maíra se expõe, dizendo como compreende as implicações dos afazeres praticados no cotidiano da roça em sua vida. Trata-se de uma narrativa de si, de como sente as experiências, enquanto filha-de-santo de um terreiro de candomblé:

\begin{abstract}
"E assim começa o meu dia...dedicada ao meu ilê...Para quem não sabe...cultivamos a humildade. Ao chegar dentro do terreiro...temos que nos desprender das alegorias do mundo. O pé no chão é para que a gente nunca esqueça de onde viemos. Diploma aqui é por meio da oralidade, antiguidade é posto e o respeito é conquistado, mas seguir a hierarquia é fundamental cumprir a sua jornada. Aqui, eu me renovo, me refaço, recebo a energia dos meus ancestrais. E ao varrer a sujeira do terreiro, limpo também minha alma. Eu, Maíra Azevedo, jornalista, youtuber, militante da luta antiracista, feminista...Eu sou a Casa de Oxumarê @casadeoxumare. Eu sou o candomblé!
\end{abstract}

\#axé \#força \#amor \#fe \#religião \#orixa"

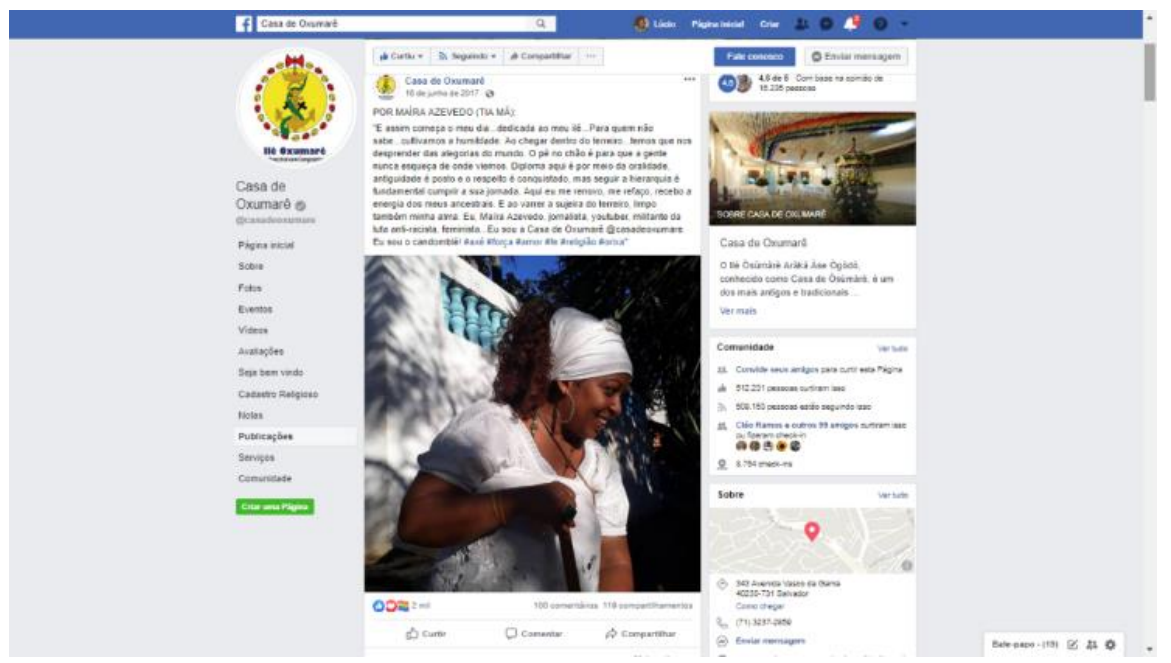

Foto 3: Maíra Azevedo varrendo escadaria da casa de Oxumarê

Fonte: Facebook, página da Casa de Oxumarê, 16/06/20117

$\mathrm{Na}$ foto 3, ela aparece de perfil, varrendo as escadarias que dão acesso ao terreiro de Oxumarê, para quem vêm pela avenida Vasco da Gama. Uma atividade simples, sem 
ostentação, sem brilhos ou holofotes, de alguém zelando do espaço religioso que lhe proporciona bem-estar e, segundo a própria, capaz de lhe renovar, refazer e acolher a energia de sua ancestralidade. Consigo dizer com precisão sua localização, na foto, por reconhecer, ao fundo um muro branco, com pilares azuis, que demarcam o início desta escadaria. Esta postagem teve duas mil curtidas com os ícones "curtir", "amei" e "orgulho LGBTI+", além de 100 comentários e 119 compartilhamentos. O perfil desta publicação traduz o entendimento desta influenciadora digital sobre o que deve ser publicitado nas redes sociais, a respeito do candomblé, postura que reafirma, durante a entrevista que fizemos:

\begin{abstract}
"toda pessoa de candomblé deveria dizer o que a gente é, de candomblé, primeiro para desmistificar. As pessoas acham que o candomblé - é isso ainda é muito vivo no senso-comum - a gente é um bando de sanguinários, assassinos, que vai pro terreiro fazer o que não presta, pra matar criancinha, tem gente que ainda diz que a gente mata criança, [...], que a gente mata animal doméstico, que a gente tá ali e faz os ebó pra matar, pra resolver, como se a gente de candomblé só vivesse de ebó"
\end{abstract}

Fazer este tipo de publicação seria uma forma de combater a discriminação, uma estratégia de desconstrução do imaginário negativo, equivocadamente, atribuído ao candomblé e seus adeptos, pois dá visibilidade a um comportamento de zelo, cuidado com a roça, cuja contra partida é despertar em seus adeptos sentimentos como purificação, renovação e humildade. E quando estes comportamentos partem de figuras com alguma projeção social e capilaridade para atingir uma número grande de pessoas, na sociedade, isto tende a produzir resultados mais significativos. Neste sentido, a internet, juntamente com as redes sociais, são "ferramentas possíveis". É o que fica demonstrado numa outra postagem de Maíra, que teve 7.200 reações (entre “curtir”, “amei” e “uau”), 685 comentários e 438 compartilhamentos.

"Se eu fosse você, não postava coisas de candomblé. Sabe como é, né? Vc é uma pessoa pública". Vira e mexe alguém me dá esse conselho. "Não deve associar sua imagem". Mas porque devo negar algo que faz parte de mim? Porque me assumir como uma religiosa, praticante e INICIADA no candomblé, pode ser prejudicial a minha imagem? Quem diz isso reconhece que vivemos em um país preconceituoso, racista e intolerante. E as religiões de matriz africana são o alvo preferencial dos insultos. Quantos pessoas não "brincam", utilizando expressões jocosas e depreciativas com nossos símbolos: "chuta que é macumba", "Devolve para o mar a oferenda"... Dizer e me assumir como pessoa de axé faz parte das minhas lutas. Não posso, não quero e não aceitarei professar a minha fé com subterfúgios. Sou de candomblé, e isso não me define, mas faz parte de mim. Negar, esconder é apagar a luta dos meus ancestrais que travaram batalhas 'oguninanas' para que hoje eu tivesse a oportunidade de sair com meu ojá, com minhas contas, pelas ruas. Não me escondo...Assumo minha fé e, justamente por ser uma pessoa pública, me sinto na obrigação de fazer isso. Justamente, para que muitas pessoas possam compreender que a religião não pode ser vista como fator impeditivo para que se ocupe determinados espaços. Eu, Maíra Azevedo, Tia Má, jornalista, youtuber, feminista, militante da luta anti racista, humorista,...Eu sou de axé, sou de candomblé. Yawô, com 12 anos de iniciação, omorixa de Oxum, barco de 4, dofona de Oxum, feita na @ casadeoxumare. Essa é a minha religião e eu não me escondo. Negar minha 
religiosidade é ceder e perder para intolerância religiosa! E eu não nasci para perder...eu vivo lutando contra tudo que oprime!

\#axé \#oxum \#candomblé \#religião \#fé \#orixá\#eusouocandomble \#casadeoxumare

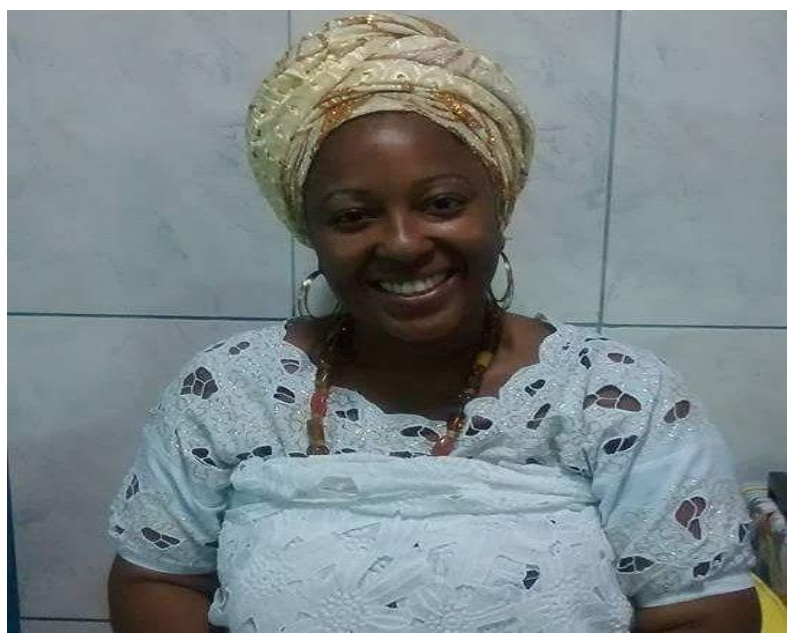

Foto4: Maira Azevedo, com trajes de candomblé e sorrindo

Fonte: Facebook, página da Tia Má, 04/06/2017

Nesta foto 4, que acompanha o texto publicado, Maíra Azevedo aparece, usando roupas e adereços de candomblé. $\mathrm{O}$ fato de estar vestida com as indumentárias, reforça sua narrativa do texto, cujo conteúdo expressa a relação adotada com o sagrado, e vai além, tratando sua identidade religiosa como ato político afirmativo, no qual não se esconde, diante dos olhares externos, valendo-se do lugar de "figura pública" enquanto estratégia de combate a intolerância contra o candomblé. Os números relativos à postagem sugerem que ela não passou despercebida, conseguindo alcance significativo nas redes, criando repercussão positiva. Se há, entre estes internautas que interagiram, alguém com desconhecimento ou visão equivocada sobre o candomblé, estes números podem indicar algum tipo de mudança, ou de sensibilização destes sujeitos.

As demais postagens seguem o mesmo princípio, de tornar públicas demandas relacionadas ao enfrentamento sócio-político das comunidades religiosas de candomblé, pelo pleno exercício de suas práticas litúrgicas, um direito já assegurado pela Constituição Brasileira, mas que se esbarra nas práticas racistas cotidianas. Como no exemplo da exposição desqualificada e distorcida, feita em torno do falecimento de uma representação importante das religiões afro-brasileira, a Iyalorixá Mãe Stela de Oxossi, líder do terreiro Ilê Axé Opo Afonja, situado em Salvador (BA) ou diante da publicações daqueles/as descontentes com 
decisão do Supremo Tribunal Federal (STF), que afirma ser direito constitucional sacralização de animais em atos religiosos:

A. no dia 23/08/2017, sobre o desconhecimento e preconceito das pessoas, com relação a sacralização do sacrifício de animais dentro do axé;

B. no dia 29/12/2018(A), sobre o uso responsável das redes sociais, a atual circulação de informações nas redes e os aspectos que caracterizam o candomblé e os cuidados que os adeptos precisam ter para não deixar desvirtuá-lo;

C. no dia 29/12/2018(B), sobre a exposição midiática com relação ao episódio na morte de Mãe Stela;

D. no dia 29/03/2019, ela questiona e denuncia equívocos nas postagens de uma internauta vegana, contrária a decisão do STF, de considerar o abate de animais em cultos sagrados como sendo constitucionais.

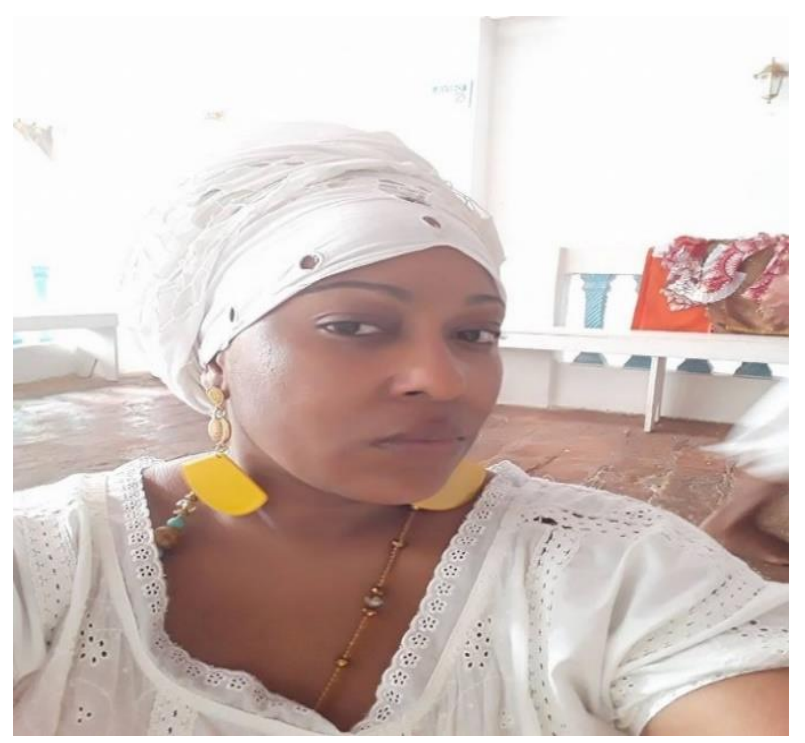

Foto 5: Maira Azevedo, com trajes de candomblé e semblante sisudo

Fonte: Facebook, página pessoal, 23/08/2017

A foto 5 refere-se a postagem "A", em que Maíra está com roupas de candomblé, expressando semblante sisudo, sem sorrir, algo pouco visto em suas postagens. O cenário desta foto é o barracão da casa de Oxumarê, local onde se realizam as festas públicas. Na postagem "B", ela repete a foto 3 , onde aparece varrendo a escadaria da roça. A postagem "C" não tem nenhuma foto, enquanto na " $D$ ", há um print da postagem da internauta vegana, sobre a qual tece severas críticas ao teor adotado pela autora. Por outro lado, Maíra deixa explícita sua posição sobre o que não deve ir para a internet e mesmo às rede sociais. 
Apresento dois registros a respeito, um na postagem "B", citada abaixo e outro da entrevista feita comigo:

\begin{abstract}
As redes sociais, hoje, contribuem para o meu sustento! E acho fundamental a gente usar a internet para dirimir preconceitos e desmitificar conceitos equivocados sobre a nossa religião! Ao mesmo tempo, sou iniciada no candomblé, uma religião de matriz africana, que tem como pilares básicos a ancestralidade, o respeito, o segredo e a manutenção por meio da oralidade. No axé, o silêncio é sagrado! Por muitos anos, o candomblé foi proibido por lei, a sua prática era uma contravenção e muitos dos nossos rituais eram realizados escondidos ou com subterfúgios! E talvez, por isso, foi virando fetiche de muitas pessoas! O proibido seduz! Falar de candomblé e dos orixás nas redes sociais virou moda! Temos até quem faz consulta por meio de aplicativos, aqueles e aquelas que realizam a associação dos orixás com astrologia e vai reduzindo toda a nossa fé ao lúdico! É lógico que isso traz audiência! Para muitos, basta falar bonito sobre o axé, já disse tudo. Sem, muitas vezes, ter dito nada que tivesse coerência! E muitas vezes, ao escrever para criticar determinadas posturas, só fazemos reafirmar! Possibilitamos, ainda mais, a folclorização de uma religião, já tratada com tanto escárnio! Todo mundo acredita que entende de candomblé! O último episódio, envolvendo a morte e o sepultamento de uma Ialorixá só atestou isso! O candomblé não demoniza ninguém! A gente crer que os orixás possibilitam que você arque com as responsabilidades das suas escolhas! Orixá é sábio, tem o seu tempo e a sua forma de dar o recado. Estamos errando! Abrimos nossas trincheiras, realizamos o fire friend e buscamos uma coerência incoerente! É preciso só saber a hora de não falar nada! De defender a religião, sem transformar em posts risíveis sobre arquétipos! Sem fazer dicotomias. Candomblé é complexo! E não existe uma forma simplista de realizar as coisas! Por isso, a importância do silêncio e de se preservar! O segredo nos assegura a continuidade e as artimanhas para driblar as perseguições! As redes sociais podem ser nossas aliadas, mas pode também ajudar a nos matar! Vonduce não vova!
\end{abstract}

(Facebook, página pessoal, 29/12/2018)

Além do dito na postagem acima, durante a entrevista, Maíra acrescentou que este ensinamento do segredo como algo sagrado é também um aprendizado adquirido em casa, com sua avó, quando lhe dizia para não contar a ninguém o que pretendia fazer. Então, diante do exposto, até aqui, a definição sobre o que pode ser publicitado ou não na internet partirá sempre do ponto de vista pessoal? Da visão de cada nó da rede?

Deter o segredo no candomblé é sinônimo de prestígio e poder, pelo menos entre os terreiros mais antigos. Saber guardar segredo representa agir como vonduce, como aquele/a que não vova ${ }^{9}$. Acessar a explicação sobre o significado de certos rituais, o fundamento dos cultos representa transpor uma barreira na qual poucos conseguem atingir, na maioria das vezes, só depois de muito tempo de presença e confiança adquirida entre os mais velhos/as. Segredo no

\footnotetext{
${ }^{9}$ Expressões usadas por Maíra, que nos foi ensinado na casa de Oxumarê
} 
candomblé equivale ao privado, é dito entre dentes, secretamente e é também uma forma particular de transmissão dos fundamentos religiosos e de manutenção do axé, a força vital. $\mathrm{O}$ uso do segredo como transmissão se justifica pela história de perseguição e estratégias de proteção desenvolvidas nestas comunidades, algo que é amplamente detalhado por Castilho, em uma das três derivações sobre ideia de segredo no culto, que elabora em sua pesquisa:

\begin{abstract}
Primeiramente, a existência de um saber secreto leva a um sistema hierárquico, segundo o qual um pequeno grupo de pessoas é encarregado da responsabilidade de acessar o conhecimento interno. Em segundo lugar, a dificuldade de acesso faz com que o saber secreto acabe sendo um bem simbólico de alto valor, o que gera uma rede complexa de relações de poder predicadas na busca para, e domínio sobre, tal saber. Uma terceira questão resulta da inserção de terreiros no contexto social externo. A longa história da perseguição ao candomblé provocou um aumento no espaço discursivo do que era considerado secreto. [...], a etnografia do candomblé, à medida que expõe o saber religioso para o olhar público, apresenta uma ameaça, pois desestabiliza o controle hierárquico sobre este saber (CASTILHO, 2010, p.32)
\end{abstract}

Contudo, com a existência do ciberaxé, dando acesso a uma infinidade de conteúdos sobre o culto, que antes eram guardadas, a sete chaves, se colocaria em dúvida estas derivações apresentadas pela autora? Desde já, afirmo que não, pelo menos, em relação as duas primeiras derivações, pois elas descrevem dinâmicas internas, condutas em meio as regras hierárquicas de membros que produzem estratégias de subversão das relações de poder e que usam de artifícios subjetivos a fim de transgredir etapas e conquistar posições hierárquicas e de prestígio na estrutura sacerdotal do candomblé. Ou seja, a existência de regras e, ao mesmo tempo, o relato da quebra destas mesmas normas, sempre fizeram parte das práticas do povode-santo.

É preciso considerar, porém, que o lugar consagrado para Exu na roça é na porteira, território fronteiriço com o mundo exterior e de onde fica sempre atento aos sinais de transformação. Castilho nos descreve um pouco destes sinais, quando analisa a terceira derivação do segredo do candomblé, em relação a sociedade externa. Ela mostra as mudanças ocorridas durante o século XX, em que ocorreu um processo gradativo de legitimação social, do culto afrobrasileiro na Bahia, que sai da condição de altamente repudiado, enquanto atividade criminosa, e passa ser objeto sob proteção do Estado, à medida que isto serve de utilidade para as políticas de turismo; sem, contudo, deixar de incluir neste processo de mudança a contribuição de outros protagonistas, como artistas, intelectuais e as várias gerações de líderes religiosos que, de formas específicas, lidaram a sua maneira com esta situação (CASTILHO, p.44, 2010). 
São estudados outros indícios de mudanças, afetando as comunidades de terreiros, em função de seus segredos ultrapassarem os limites da comunidade religiosa, por exemplo, em Braga $(1998)^{10}$, através dos comportamentos dos "indaka de kafurungoma", ou dos fuxiqueiros de candomblé; e, mais recentemente, em Lopes (2012) e Silva (2013), que transitam no mesmo campo de pesquisa no qual me incluo, candomblé e internet, trazendo em suas discussões o papel dos estudiosos da religiões afro-brasileiras, em especial, da antropologia, ao produzir material escrito sobre conteúdos litúrgicos que circulam, não só entre o do povo-de-santo, mas noutras comunidades, sobretudo, com o advento das redes sociais virtuais. Assim, são compartilhados vídeos, fotos, narrativas adquiridas em condições singulares ao processo investigativo, mas depois, se tornam públicas e, algumas vezes, desconexas das circunstâncias reais de origem.

Até nossa interlocutora Maíra indaga estes sinais, que é um fenômeno tão presente na rede ciberaxé. Na postagem citada acima, tem um trecho no qual diz que o segredo vem "virando fetiche de muitas pessoas! O pró́bido seduz!". Ora, o fetiche, o exótico, o singular aparece na composição do perfis dos internautas, ao estabelecerem interações na rede (RECUERO, 2008). Além disso, tem se tornado um parâmetro de sucesso e prestígio socioeconômico, daí, um meio do sujeito ganhar visibilidade nas mídias sociais. Na continuidade do texto postado, ela faz referência a uma comportamento muito corriqueiro, na redes sociais, em que qualquer internauta se sente à vontade para opinar diante de qualquer publicação e assunto, independente de seu nível de domínio e competência: "Falar de candomblé e dos orixás nas redes sociais virou moda! Temos até quem faz consulta por meio de aplicativos, aqueles e aquelas que realizam a associação dos orixás com astrologia e vai reduzindo toda a nossa fé ao lúdico". Sua crítica, neste trecho, está endereçada ao tornar público, assuntos relacionados ao candomblé, motivada por interesses publicitários, de uma propaganda estritamente estilizada. Este raciocínio se reforça quando diz a frase: "É lógico que isso traz audiência!"

Portanto, respondendo à questão, inicialmente, feita, eu acredito que será sim sempre uma escolha individual, daquele/a que manuseia o mouse, sobre o que deverá, ou não, ser tornado público. Isto porque as pessoas estão se voltando mais para si, desenvolveram arbítrio individual; adquiriram anseios que são mobilizados tanto por temáticas diversas, a partir de movimentos coletivos ou, com base em inquietações individuais, mas sempre se colocando mais no centro das preocupações. Não acredito que seja um mudança que vêm ocorrendo de forma homogênea; elas acontecem em distintos tempos e processos. É nesta dinâmica que as

\footnotetext{
${ }^{10}$ Esta é uma interpretação minha, de que a socialização de segredos do culto pode indicar indícios de mudança nestas comunidade. A obra citada do professor Júlio Braga não faz esta discussão.
} 
pessoas têm chegado às comunidades de candomblé, com olhos mais atentos sobre si, porém, em um ambiente onde o coletivo é um valor. Isto tem gerado tensões, em função do individual não se submeter ao coletivo e vice-versa.

É um processo de transformação, que acredito, nos afetar, devido a fatores diversos. São alterações que tem estimulado certos campos da existência humana, mais do que outros e uma amostra disso é com relação ao que se compreende como sendo do âmbito privado. A definição sobre o que é o "privado" foi sendo elaborada ao longo dos séculos e das culturas. Só para ilustrar, Sibília faz referência ao livro de WitoldRybcznski ${ }^{11}$, sobre estória da casa, no qual o autor explica que, no século XVI, era raro a existência de uma quarto para um único sujeito. Os ambientes, dos quais era possível retirar a visão do público, só ocorreria no início do século XVIII, ainda assim, a noção de que tais ambientes deviam ser confortáveis e silenciosos se restringiriam aos homens mais afortunados. (SIBILIA,p.86, 2016).

Sibília explica que o ambiente privado se tornará importante, no século XIX, com o pleno auge da cultura burguesa, oferecendo os requisitos básicos para o desenvolvimento do eu, e para o transcorrer da intimidade. Era nestes cenários, que se engendrava os relatos de si, através dos gêneros autobiográficos, das cartas e dos diários tradicionais, com as escritas intimas. São narrativas de estatuto ambíguo, transitando o limite entre "as belas artes textuais e o documento extraliterário de valor meramente testemunhal" sobre modos de vida de um dado tempo e lugar. Este escritos, continua Sibília, são catalogados como pertencentes a um gênero de menor valor, esteticamente, ou "como formas não canônicas do literário". Contudo, afirma a autora, tem ocorrido mudanças em função do interesse que diversas áreas do conhecimento desenvolveram pela vida cotidiana de pessoas comuns, fazendo destes depoimentos pessoais algo de maior valor para certas regiões do saber, dedicadas "à procura de preciosos tesouros de sentido", afirma a autora.

Dentre estas novas áreas de conhecimento temos a da reprodutibilidade digital que sob estímulo do mercado, tem incrementando o interesse por obras que conservam uma espécie de aura ou que lhe atribui características únicas, não importando que sejam "de qualquer um: pessoas como eu, você, e todos nós”. Este é mais um fenômeno que chama a atenção de Sibília, porque, a princípio, eram narrativas que careciam da solidão do autor durante sua

\footnotetext{
${ }^{11}$ RYBCZNSKI, Witold. Lá casa: história de uma vida. Buenos Aires: Emece, 1991, p.29
} 
criação, distância espacial e temporal dos destinatários das cartas ou dos eventuais leitores dos diários, este últimos só tendo acesso sob condições especiais (morte do autor, por exemplo). Entretanto:

As versões cibernética destas escritas de si, por sua vez, também costuma ser práticas solidárias, embora seu estatuto seja bem mais ambíguo porque elas se instalam no limiar da publicidade total. A tela de nossos computadores não é tão sólida e opaca como os muros dos antigos quartos próprios. Em vez disso, parecem janelas abertas ao público. Por outro lado, a distância espacial e temporal com relação aos leitores ou espectadores tem encolhido sensivelmente (Idem, p.87)

Esta ideia pode servir de explicação para uma das muitas transformações pelos quais as pessoas têm passando, nos tempos atuais, no campo da subjetividade, na forma como estão desenvolvendo a percepção sobre si, diante da relação estabelecida com as tecnologias comunicacionais virtuais. O que antes dependia da privacidade de um quarto, hoje não é mais um requisito. A motivação agora está em tornar-se visível pelas redes sociais, é conquistar vários "likes" e compartilhamentos, o que em alguns casos pode render-lhe ganhos financeiros ${ }^{12}$. A oportunidade de "criar" um ato, uma expressão, "capturar" um instante, um acontecimento inusitado, capaz de causar impacto na rede tende a motivar os internautas. Estes flashs de "criação" ou de "captura" do inusitado não precisam, necessariamente, ocorrer em ambiente privado, cercado por paredes, como em um quarto, sala ou cômoda. Basta o livre arbítrio de quem está por traz das lentes em decidir registrar. Cria-se uma onda comportamental que, em rede, se irradia velozmente ganhando adeptos nos mais diferentes grupos sociais.

Mesmo, entre o povo-de-santo, a princípio, "lincado" a ideia do "segredo" como pilar fundamental de seu sistema religioso, mostra-se na encruzilhada, através de infinita quantidade de material disponível em áudio, vídeo, imagem e texto na rede ciberaxé. Ao que parece, nestas novas circunstâncias, as descobertas no âmbito do sagrado só adquirirem significação para estes indivíduos, se compartilhadas com as pessoas. Talvez uma espécie de quarta derivação decorrente das três, inicialmente, sugeridas por Castilho (2010), em que o prestígio é atribuído a quem mais repassa ou revela "segredos", sem preocupar-se em romper os limites e regulações hierárquicas, interferindo nas relações de poder estabelecidas a partir da posse do segredo, visto que a difusão virtual deste promove, além da ampla capilaridade, a possibilidade de não discriminar quem o acessa por tais vias pois, algumas vezes, são repassadas por lideranças legitimas do candomblé.

\footnotetext{
${ }^{12}$ No caso dos/as Influenciadores digitais e youtuber para os vídeos
} 
Neste sentido, uma outra nuance deste processo toma forma e merece atenção. A intensidade com que os equipamentos móveis de comunicação, conectados à internet, com inúmeras possibilidades funcionais, ao se integrarem em nossos afazeres cotidianos, tornam-se verdadeiras extensões de nós mesmos. Uma interface, entre sujeito e máquina, que corrobora para que os novos meios de socialização ocorram a um clic, livrando-nos, a princípio, daqueles conflitos comuns das interações no mundo não virtual, do tipo off-line. Uma suposta tranquilidade, que nos deixa mais livres para exercitar protagonismos virtuais, nos permitindo o mergulho em nossas inquietações e sentimentos, porque temos como salvaguarda a frieza do contato com a tela do computador, associada a possibilidade de escolhermos representações capazes de mascarar quem somos na rede.

\section{REFERÊNCIAS}

AZEVEDO, Maira. Se eu fosse você não postava coisas de candomblé. Salvador. 04/06/2017. Facebook: página pessoal.

https://www.facebook.com/dicasdatiama/photos/a.1038448752856447/155020513834740/?ty pe $=3$

AZEVEDO, Maira. E assim começa o meu dia....Salvador,16/06/2017. Facebook: Casa de Oxumarê. https://www.facebook.com/casadeoxumare/posts/1484365011586732:0

AZEVEDO, Maira. Sou iniciada, raspada, catulada no Candomblé há 12 anos. Salvador, 23/08/2017. Facebook: página pessoal.

https://www.facebook.com/maira.azevedo25/posts/1861159403900873

AZEVEDO, Maira. As redes sociais, hoje, contribuem para o meu sustento! Salvador, Dia 29/12/2018 (A). Facebook: página pessoal.

https://www.facebook.com/maira.azevedo25/posts/2510495772300563

AZEVEDO, Maira. Só me dói perceber... Salvador, 29/12/2018 (B). Facebook: página pessoal. https://www.facebook.com/maira.azevedo25/posts/2510451392305001

AZEVEDO, Maira. LEVIANA OU IGNORANTE?? Salvador, 29/03/2019. Facebook: página pessoal. https://www.facebook.com/dicasdatiama/posts/2377685712266071:0

BRAGA, Júlio. Fuxico no Candomblé: estudos afro-brasileiros. Feira de Santana: UEFS, 1988. 
CASTELL, Manuel. A Galáxia da Internet: reflexões sobre internet, os negócios e a sociedade. Rio de Janeiro; Zahar Ed., 2003

CASTILHO, Lisa Earl. Entre a oralidade e a escrita: a etnografia dos candomblés da Bahia. Salvador: EDUFBA, 2010.

GUATARRI, Felix. CAOSMOSE: um novo paradigma estético. Rio de Janeiro; Editora 34, 1992

LOPES, Emmanuel Bastos de Magalhães. Ebó-Virtual: internet, candomblé e disputas simbólicas em Fortaleza, Recife: UFPE, Programa de Pós Graduação em Antropologia. Dissertação, 2012.

PAZ, Adilson Meneses da. PEDRINHA MIUDINHA EM ARUANDA Ê, LAJEDO: o modo de vida da umbanda. Salvador; UFBA. Programa de Doutorado Multi-institucional e Multidisciplinar em Difusão do Conhecimento. Tese, 2019.

RECUERO, Raquel. Redes Sociais na Internet. Porto Alegre: Sulina, 2009.

SANTAElla, Lúcia. Culturas e Artes do Pós-humano: da cultura das mídias à cibercultura. São Paulo; Paulus, 2003.

SIBÍlLIA, Paula. Show do Eu: A intimidade como espetáculo. $2^{\text {a }}$ Ed. Contraponto, Rio de Janeiro; RJ, 2016.

SILVA, Patrícia Ferreira e. AXÉ-ONLINE: a presença das religiões afro-brasileiras no ciberespaço. São Paulo: USP, Programa de Pós Graduação em Antropologia Social. Dissertação, 2013

Este é um artigo de acesso aberto distribuído sob os termos da Licença Creative Commons Atribuição Não Comercial-Compartilha Igual (CC BYNC- 4.0), que permite uso, distribuição e reprodução para fins não comerciais, com a citação dos autores e da fonte original e sob a mesma licença. 